\title{
Tres
}

\section{Las emociones}

\section{políticas}

DOI: 10.29236/sistemas.n158a8

\section{Una ampliación de capacidades para el desarrollo sostenible.}

\section{Resumen}

No hay desarrollo sostenible sin desarrollo humano y no hay desarrollo humano sin el cultivo de emociones políticas como el amor, la solidaridad y la compasión. Estas son virtudes posibles desde una educación emocional a lo largo de la vida de la persona, como imperativo para el ejercicio de una ciudadanía activa que pueda ser y hacer posible habitar nuestra casa común de manera responsable, ante los desafíos contemporáneos como el cambio climático, los desplazamientos forzados de poblaciones, las violencias y la pandemia con sus impactos económicos y sociales.

El documento contiene tres partes, en la primera una justificación de las causas actuales de insostenibilidad planetaria; en la segunda un énfasis en la premisa: no hay desarrollo sostenible, sin desarrollo humano; $y$, en la tercera, contemplará el hecho de que no hay desarrollo humano sin el cultivo de emociones políticas, necesarias para una sociedad decente y sostenible.

\section{Palabras clave}

Crisis civilizatoria, desarrollo sostenible, capacidades básicas humanas, desarrollo humano y emociones políticas. 


\section{Introducción}

Vivimos momentos críticos de humanidad; una crisis civilizatoria y planetaria con una degradación de la vida colectiva y ecológica, resultado de un modelo productivo hoy día en exceso consumista, despilfarrador y en consecuencia contaminante.

Esta crisis nos plantea el exigente y decisivo camino hacia la sostenibilidad, que nos haga viable como especie y con el respeto por otras formas de vida, con un planeta en equilibrio, una sostenibilidad como modo de ser y estar con la Madre Tierra, de actuar de manera coherente, valorando a cada instante las implicaciones de nuestras maneras de ser y estar consigo mismos, con los otros y con el planeta, en un vínculo estrecho con destino común, incluidos los aprendizajes, que ojalá asumamos, derivados de la pandemia COVID-19.

En este sentido, la ONU (2021) señala en su informe reciente "Hacer las paces con la naturaleza" que, el cambio climático, la pérdida de biodiversidad y la contaminación se constituyen en tres emergencias que requieren ser abordadas de manera integral y decisiva, con una transformación de nuestro sistema de producción y consumo que haga posible un desarrollo sostenible viable para las generaciones actuales y futuras.
El desarrollo sostenible, además de una práctica en la vida cotidiana, es un saber que debe comprender a todas las áreas del conocimiento, desde las ciencias exactas, naturales hasta las sociales y humanas.

En ese orden de ideas, los problemas planteados por la ingeniería no responden a los generados exclusivamente por factores tecnológicos y económicos, sino por aspectos políticos, éticos, sociales y humanos, porque finalmente, es la Madre Tierra y la humanidad como parte de ella, la impactada por el uso de la tecnología. Ramallo, M.; Cardaci, K; Douglas C., Leonardo A. (2017).

Por esta razón es que la ingeniería de sistemas debe repensar el desarrollo sostenible desde la generación y aplicación de conocimiento técnico-científico, considerando sus impactos, para contribuir con la preservación de un planeta en equilibrio, aún para los que no han nacido. Gonzáles Sánchez, J. L. (2013)

Es decir, que nuestros patrones de producción y consumo han deteriorado nuestra vida y la de otras especies, por lo que se requieren cambios radicales tanto individuales como colectivos; por esto es necesario, en primer lugar, comprender nuestra insostenibilidad planetaria y cultivar emociones públicas para enfrentar los retos que hagan 
posible la sostenibilidad intergeneracional.

\section{Causas de insostenibilidad planetaria}

La crisis civilizatoria de hoy representa en sí misma una crisis de humanidad de la persona y de sus vínculos no solamente entre sus congéneres, sino con otros seres vivos y en consecuencia con la Madre Tierra.

Esta crisis nos convoca al imperativo de comprender la dimensión del deterioro de nuestra casa común, nuestro planeta y transformar nuestra manera de establecer los vínculos entre nosotros, y de manera expansiva con la naturaleza, aprender a habitarla desde emociones políticas, sin hacer daño.

En este sentido Boff (2012) plantea la urgente necesidad de la civilización actual de pensar posibles alternativas frente al modelo de "desarrollo" actual, por su insostenibilidad, dado que como humanidad hemos perdido toda conexión con nuestra casa común. Plantea el autor seis causas de insostenibilidad que bien vale la pena analizar (complementado con otros autores) porque nos hacen repensar sobre nuestros modos de pensar y actuar en aras de construir nuestro futuro, incluido el de los que no haya llegado.

Señala Boff (2012) seis causas de insostenibilidad orden ecológico social actual, que dan cuenta del porqué de esa expresión depredadora y cosificante de nuestra casa común, causas que presentamos a continuación:

Primera causa: El proyecto de modernidad como promesa de libertad, razón y progreso (S. XVI) y la visión de la Tierra, como cosa y baúl de recursos.

Esta causa de insostenibilidad la identifica Boff (2012) con la relación que hemos establecido como especie con la Tierra como "cosa y baúl de recursos". Se sustenta en el dualismo ser humano y naturaleza, situándose el ser humano fuera del vínculo con la tierra, identificándola más como "cosa" a la que se debe extraer los recursos inagotables para su propio beneficio, sin retribución y sin respeto, con destrucción de su biodiversidad porque pasa a ser objeto de "uso y abuso por parte de los humanos." (Boff, 2012:69)

Es decir, que predomina una relación extractiva con la madre naturaleza, con implicaciones en ocasiones irreparables por contaminación y destrucción de la biodiversidad, puesto que se prioriza el modelo tecnoproductivo.

Segunda causa: El antropocentrismo ilusorio: En la consideración de la Madre Tierra como "cosa", el ser humano se ubica en el centro de todas las cosas, amo y dueño de la naturaleza, pues NO se considera parte de ella; contamina sus 
aguas, deteriora y agota sus suelos, la explota como "cosa", de suerte que, toda forma de vida se convierte en su propiedad.

Es una expresión de antropocentrismo ilusorio que nos está convirtiendo como especie destructora de sí misma y de otras formas de vida, olvidando que el ser humano es parte de la Naturaleza, que se debe a ella.

La prioridad del hombre sobre la naturaleza creó desequilibrio y un modelo extractivista de sobreexplotación por el que costará muchos años restablecer el planeta.

Tercera causa: Los asuntos sin resolver del proyecto de la Modernidad: El imposible progreso ilimitado con crecimiento lineal en un planeta finito. En esta casusa de insostenibilidad Boff nos recuerda nuestro abusivo consumo: "la tierra limitada no soporta un proyecto ilimitado" (Boff, 2012: 72) de la actual civilización. Con el proyecto de modernidad se propició el escamoteo de recursos naturales, formas de explotación y barbarie del hombre por el hombre, conduciendo a extremos de enorme riqueza y de inmensa pobreza, desde diferentes puntos geográficos de este mundo globalizado, que manifiesta día a día las expresiones de injusticia, de hambre de pueblos y devastación de la Madre Tierra.

Así mismo, el consumismo compulsivo nos ha llevado a hacer prevale- cer el "lo quiero" por sobre "lo necesito". Este exagerado consumo genera diariamente toneladas y toneladas de desechos de todo tipo, incluidos los desechos electrónicos, el uso excesivo de papel, entre otros. González Sánchez, J. L. (2013)

Cuarta causa: Visión parcial, mecanicista y patriarcal. La vida fragmentada nos ha impedido tener una visión holística de nuestra condición como parte de nuestro universo, olvidando que los actos de la vida de cada ser humano tienen una resonancia en los otros. El "Olvido que la unión de las partes forma un todo orgánico".

El patriarcalismo se ha deslizado en todas las esferas de la vida, en la pública y en la privada. Ha cooptado las instituciones, el Estado, la vida económica, social y cultural, deshumanizando las relaciones entre hombres y mujeres, a ella se la ha hecho invisible, subordinada. No hay ningún país del mundo que respete en su totalidad a sus mujeres.

La construcción de lo masculino sobre lo femenino desde la relación dominación-subordinación, promueve el ejercicio de la violencia por parte de quien domina, y al mismo tiempo la legítima al no denunciarla, penalizarla y evitar que suceda.

En este orden de ideas, el guion masculino de la violencia señala 
Eisler (2000), parte de una ideología en la cual los machos se consideran superiores a las hembras, y las emociones asociadas con la masculinidad, superiores a aquellas asociadas con la feminidad. Estos guiones enseñan a los hombres que sólo cierto tipo de sentimientos son <masculinos>: el disgusto, la rabia, el desprecio. En otras palabras, sentimientos apropiados para quienes van a dominar. También les enseñan a despreciar sentimientos "femeninos inferiores" como la angustia, la compasión, la empatía, así como la socialización femenina estereotipada enseña a las mujeres que los sentimientos "masculinos" que ellas (al igual que los hombres) también consideran superiores, son inalcanzables para ellas.

Eisler (2000) citando a Mosher y Tomkins, refiere que la socialización de los niños y las niñas para una $<$ masculinidad $>$ y $<$ feminidad $>$ androcráticas, desarrolla estereotipos para el ejercicio de ser dominadores y dominadas. "En estas familias se ve en forma más vívida cómo se enseña sistemáticamente a los niños que es vergonzoso expresar (o incluso sentir) emociones <suaves>, que esos sentimientos son apropiados sólo para niñas o mujeres <inferiores> o para hombres <afeminados> que no sólo son castigados por expresar tales sentimientos, sino porque al hacerlo están siendo <femeninos> en lugar de <masculinos>". (Eisler, 2000: 71)
Esta construcción cultural dominador-subordinada exige hoy, más que nunca, la resignificación de la relación entre hombres y mujeres desde "siete principios normativos básicos: la antipobreza, la antiexplotación, la igualdad en el ingreso, la igualdad en el tiempo libre, la igualdad en el respeto, la antimar ginación y el antiandrocentrismo. (Fraser, 1997)

Quinta causa: El individualismo y la dinámica de competición. Señala Boff que para la razón de ser del sistema capitalista es la propiedad privada y la apropiación individual de los beneficios del desarrollo, porque "el individualismo se conjuga plenamente con el espíritu de competición, motor fundamental de la acumulación capitalista." (Boff, 2012:75)

Requerimos pasar del yo al nosotros, como alternativa a la tragedia que ya empezamos a vivir. Afrontar desde el nosotros la catástrofe que hemos construido, se constituye en la única posibilidad para afrontarla.

Sexta y última causa: Primacía del desperdicio sobre el cuidado, del capital material sobre el capital humano. Desde esta causa de insostenibilidad se señala el derroche y destrucción de los recursos de la Madre Tierra, la creación de una cultura de consumo desbordada de bienes materiales que priorizan el tener sobre el Ser; se ha menospreciado la dimensión espiritual que da sentido a la humani- 
dad, sentido de la vida, de creación de un cultivo de cuidado expansivo del sí mismo, del cuidado de los otros y del cuidado de la Madre Tierra.

Ante estas seis causas de insostenibilidad planteamos como luz de esperanza las posibilidades que arroja el paradigma del Desarrollo Humano (DH) como una apuesta, entre otras, que nos haga posible un proyecto de humanidad en convivencia con otros seres vivos y en consecuencia con el planeta. Este paradigma ha tenido importantes avances desde la década de los 90 del siglo XX hasta nuestros días; introduce una definición radicalmente nueva del desarrollo. (UL HAQ Mahbub, 2003)

El (DH) parte de la premisa de considerar que la verdadera riqueza de una nación está en su gente, por ello considera que el objetivo básico del desarrollo es crear un ambiente propicio para que los seres humanos amplíen capacidades y disfruten de una vida prolongada, el acceso a conocimientos, de recursos suficientes, y le asigna una importancia determinante a la libertad política, la creatividad, y la dignidad de la persona. (PNUD, 1990)

\section{No hay desarrollo sostenible, sin desarrollo humano}

Garantizar el acceso a la realización de capacidades permitirá establecer un vínculo amoroso con la Madre Tierra que contrarreste la expresión depredadora y cosifi- cante de nuestra casa común. Con un umbral mínimo de desarrollo humano, el desarrollo sostenible será viable, lo que implica que todos los seres humanos accedan a una ampliación de capacidades básicas como expresión de justicia social.

- Justicia social como la realización de capacidades básicas humanas.

Nussbaum a lo largo de su obra (1997, 2000, 2001, 2012, 2014, $2018,2019)$ ha venido planteando en torno a la justicia social la importancia de proteger un conjunto de oportunidades humanas o capacidades básicas para todos los seres humanos. Opciones humanas que permitan un "umbral apropiado" hacia un desarrollo justo, que todo Estado tiene el deber de garantizar. (Nussbaum, 2018)

Esas capacidades básicas humanas son inherentes a la persona y hacen posible su desarrollo y una vida digna. Se trata de una teoría parcial de la justicia social desde el potencial que tiene toda persona para Ser y Hacer a lo largo de su vida; por tanto, de crear las oportunida-des para que los ciudadanos y ciudadanas de una nación puedan superar el umbral de capacidad con libertad para elegir y actuar, "Eso es lo que significa tratar a todas las personas con igual respeto." (Nussbaum, 2012:44)

En este sentido no se trata desde esta perspectiva de una política 
que mejore la situación de un grupo determinado, se trata de promover capacidades para todas y cada una de las personas, con asistencia digna, situando el desarrollo desde la tradición liberal, "La individualidad, la libertad y la capacidad de elección siguen siendo bienes, y muy importantes". (Nussbaum, 2006: 219)

Contrario a esta capacidad de elección libre de la persona en nuestro contexto el asistencialismo, representado por políticas neoconservadoras, ha venido a lo largo de los años dando respuesta a la condición de los más vulnerables. Con este enfoque se han perpetuado condiciones de pobreza, lo que constituye la negación fundamental de los derechos humanos, haciendo creer a los más pobres que se les ayuda. Porque el "asistencialismo es una política destinada a construir una relación social de dominación para generar una cultura política de dependencia de los "asistidos" del Estado, de los políticos y de la "generosidad" de los ricos, en lugar de promover una cultura basada en la emancipación de las personas de las condiciones materiales que no les permiten vivir con dignidad. (Bustelo, 1999:76)

¿Pero a qué capacidades básicas humanas se refiere Nussbaum? Señala la autora que "un orden político aceptable está obligado a procurar a todos los ciudadanos y ciudadanas un nivel umbral de las siguientes 10 capacidades: vida, sa- lud Física, integridad física, -sentidos imaginación y pensamiento-, emociones, razón práctica, afiliación, otras especies, juego, control sobre el propio entrono." (Nussbaum, 2012: 53, 54)

En este orden de ideas, además de la responsabilidad del Estado en la garantía de estas capacidades, se requiere de una sociedad justa y decente que las proteja desde vínculos de confianza y sentimientos morales. (Nussbaum, 2018)

\section{No hay desarrollo humano sin el cultivo de emociones políticas, en una sociedad decente y justa}

Hemos identificado que de las 10 capacidades básicas humanas propuestas por Nussbaum (2012) las emociones forman parte de este listado, definiéndolas como:

"Poder mantener relaciones afectivas con personas y objetos distintos de nosotros mismos; poder amar a aquellos que nos aman y se preocupan por nosotros, y dolernos por su ausencia; en general, poder amar, penar, experimentar ansia, gratitud y enfado justificado. Que nuestro desarrollo emocional no quede bloqueado por el miedo y la ansiedad. (Defender esta capacidad supone defender formas da asociación humana de importancia crucial y demostrable para este desarrollo." (Nussbaum, 2006:88)

Hecha la aclaración anterior, una pregunta recurrente a lo largo de la 
obra de la autora es ¿Porque son tan importantes las emociones en la construcción de una sociedad decente? $Y$ de manera reiterativa afirma la autora: "Las emociones pueden desestabilizar una comunidad y fragmentarla, o bien pueden ayudar a que cooperemos mejor y a que pongamos mayor ahínco en conseguir la justicia. (Nussbaum, 2019:36)

Es decir, el cultivo de emociones es fundamental en el logro de una soiedad justa, porque es a través de las emociones públicas o políticas que construimos lazos de cooperación y solidaridad.

Y anota en este sentido, "Las emociones no vienen predeterminadas de forma innata, sino que se van moldeando de innumerables maneras mediante los contextos y las normas sociales. Disponemos de un margen considerable para moldear las emociones de nuestra propia cultura política." (2019:36)

Entonces, comprendemos que las emociones se pueden moldear y en este proceso los contextos y las normas sociales son fundamentales, porque es a partir de esta construcción social que edificamos nuestra propia cultura política, o en su defecto la carencia de ésta. Las emociones nos permiten conseguir la justicia, pero debemos cultivarlas desde la vida examinada, porque ellas no vienen de manera innata, y porque no todas las emociones nos permiten este propósito, como en el caso de la ira, el miedo, el odio, el asco, la envidia. Entonces nos corresponde a cada uno de nosotros cultivar emociones amorosas de solidaridad, compasión y esperanza que favorezcan las buenas aspiraciones democráticas de un proyecto político cuyo fin sea el respeto a las libertades políticas, la igualdad de oportunidades para la generación de riqueza y de bienestar desde el acceso a la salud, la educación y vida decente, en pos de un mejor futuro y en la realización de los ideales de justicia social.

Para Nussbaum (1997) la vida examinada desde el ideal socrático implica el examen crítico de uno mismo, de las tradiciones y costumbres, como ejercicio de una ciudadanía reflexiva porque permite liberar la mente, formando personas con agudeza mental, como ciudadanos del mundo. Una ciudadanía reflexiva puede pensar por sí misma, y cultivar emociones "con solidez del razonamiento de la exactitud de los hechos y la precisión del juicio" (Nussbaum,1997:28), con la intención de unir amorosamente a los ciudadanos no tanto en situaciones de normalidad y armonía, sino justamente en momentos críticos, en aras de sacrificar su interés particular por el bienestar común.

Significa entonces, que el amor como emoción política por excelencia, debe ser cultivada porque ella contiene múltiples expresiones. Desde este sentimiento favorece- 
mos vínculos sociales y superamos obstáculos que nos los impiden. Con esta emoción tan poderosa, construimos lazos que favorecen nuestra vida colectiva, no sólo como especie, sino con otros seres vivos que requieren de nuestro respeto; es por esta razón que desde el cultivo de un sentimiento como este podemos hacer viable un planeta sostenible.

Con el cultivo de la expresión amorosa, brotan sentimientos como la solidaridad y la compasión que hacen posible, en la experiencia humana, descentrarnos del yo para construir el nosotros, para comprender que hay otros que sufren y moralmente reprochar ese sufrimiento por el daño que causa, porque la moralidad actúa de la mano del amor, implica reciprocidad democrática. (Nussbaum, 2019)

Dicho lo anterior, para que el amor florezca, siguiendo a Winnicott desde Nussbaum (2019), se requiere de ambientes facilitadores, de ellos el primero, la familia, que debe contener una estabilidad afectuosa, y desde la sociedad, una ausencia básica de violencia y de caos, de temores de persecución étnica, de terror y miedo, como lo es la experiencia de la guerra; porque el miedo nos hace desconfiados, ante el sentimiento de amenaza inminente a nuestro propio bienestar. Concluye Nussbaum que cultivar emociones desde el amor es una expresión de felicidad y justicia. Nussbaum (2019)

\section{Conclusiones}

Los desafíos contemporáneos en materia de sostenibilidad planetaria nos exigen asumir nuevos relacionamientos con la Madre Tierra.

Estos nuevos relacionacionamientos requieren ser cultivados desde la vida examinada con emociones políticas que a manera de capacidades nos comprometan con un desarrollo sostenible para las actuales y futuras generaciones.

\section{Referencias}

Bustelo, E. (1999) Pobreza Moral. Reflexiones sobre la política social amoral y la utopía posible. En: Corredor, C. (Ed.) Pobreza y Desigualdad. Reflexiones conceptuales y de medición. Universidad Nacional de Colombia, Bogotá.

COLCIENCIAS, CINEP, GTZ.

Boff, L. (2012). La sostenibilidad. Qué es y qué no es. México. Dabar.

Eisler, R. (2000). Nuevos Caminos hacia el poderpersonal yel amor. México. Pax.

Fraser, N. (1997). Iustitia Interrupta. Reflexiones críticas desde la posición "postsocialista". Bogotá D.C: Universidad de los Andes. Siglo del Hombre Colombia. Editores.

González, J. L. (2013) El desarrollo sostenible y la ingeniería en sistemas computacionales. Recuperado de: https://nyan5.wordpress.com/ 2013/04/28/79/

Nussbaum M. (1997) El Cultivo de la Humanidad. Una defensa clásica 
de la educación liberal. Barcelona. Paidós.

Nussbaum M. (2000) Las Mujeres y el desarrollo Humano. Barcelona. Herder.

Nussbaum M. (2001) Paisajes de Pensamiento. Barcelona. Paidos.

Nussbaum M. (2006) Las Fronteras de la Justicia. Consideraciones sobre la exclusión. Barcelona. Paidos.

Nussbaum M. (2012). Crear capacidades. Propuesta para el desarrollo humano. Barcelona. Paidós.

Nussbaum M. (2014) Emociones políticas. ¿Por qué el amor es importante para la justicia? Barcelona. Paidos.

Nussbaum M. (2018) La ira y el perdón. Resentimiento, generosidad, justicia. México. Fondo de cultura Económica.

Nussbaum M. (2019). La monarquía del miedo. Una mirada filosófica a la crisis política actual. Bogotá.

Planeta.
UI Haq M. (2003) Paradigma del Desarrollo Humano. Oxford University Press. Recuperado de:

http://www.desarrollohumano.cl/pd f/1995/paradigma95.pdf

PNUD. (1990) Informe Sobre Desarrollo Humano Madrid.

Tercer Mundo Editores.

ONU Programa de las Naciones Unidas para el Medio Ambiente (2021). Hacer las paces con la naturaleza: Plan científico para hacer frente a las emergencias del clima, la biodiversidad y la contaminación.

Nairobi.

Recuperado de:

https://www.unep.org/resources/m aking-peace-nature.

Ramallo, M.; Cardaci, K; Douglas C., Leonardo A. (2017) El desarrollo sostenible (DS) en la formación de ingenieros: un nuevo campo para repensar la perspectiva CTS.

Recuperado de:

Revista Tecnologia e Sociedade, vol. 13, núm. 28, mayo-agosto, 2017, pp. 1-17 Curitiba, Brasil. Universidade Tecnológica Federal do Paraná.

María Inés Baquero Torres. Doctora en Educación de la Universidad Distrital Francisco José de Caldas. Con maestría en Urbanismo, Geografía y Ordenamiento Territorial, de la Universidad de la Sorbona, Paris III. Máster en Educación en Valores para la Democracia en Ibero América, de la Universidad de Barcelona. Especialista en Cooperación Internacional y Gestión de Proyectos para el Desarrollo y Trabajadora Social de la Universidad Externado de Colombia. Su experiencia docente contempla la Universidad Externado de Colombia, Universidad Nacional de Colombia, Universidad del Rosario, Universidad de La Salle. Actualmente profesora de la Universidad de Manizales. Consultora en Desarrollo Sostenible y Políticas Públicas con enfoque de Desarrollo Humano. Investigadora social en áreas de educación ambiental, políticas públicas sociales, políticas poblacionales y conflicto armado colombiano. 


\section{JORNADA DE GERENCIA DE PROYECTOS TI}

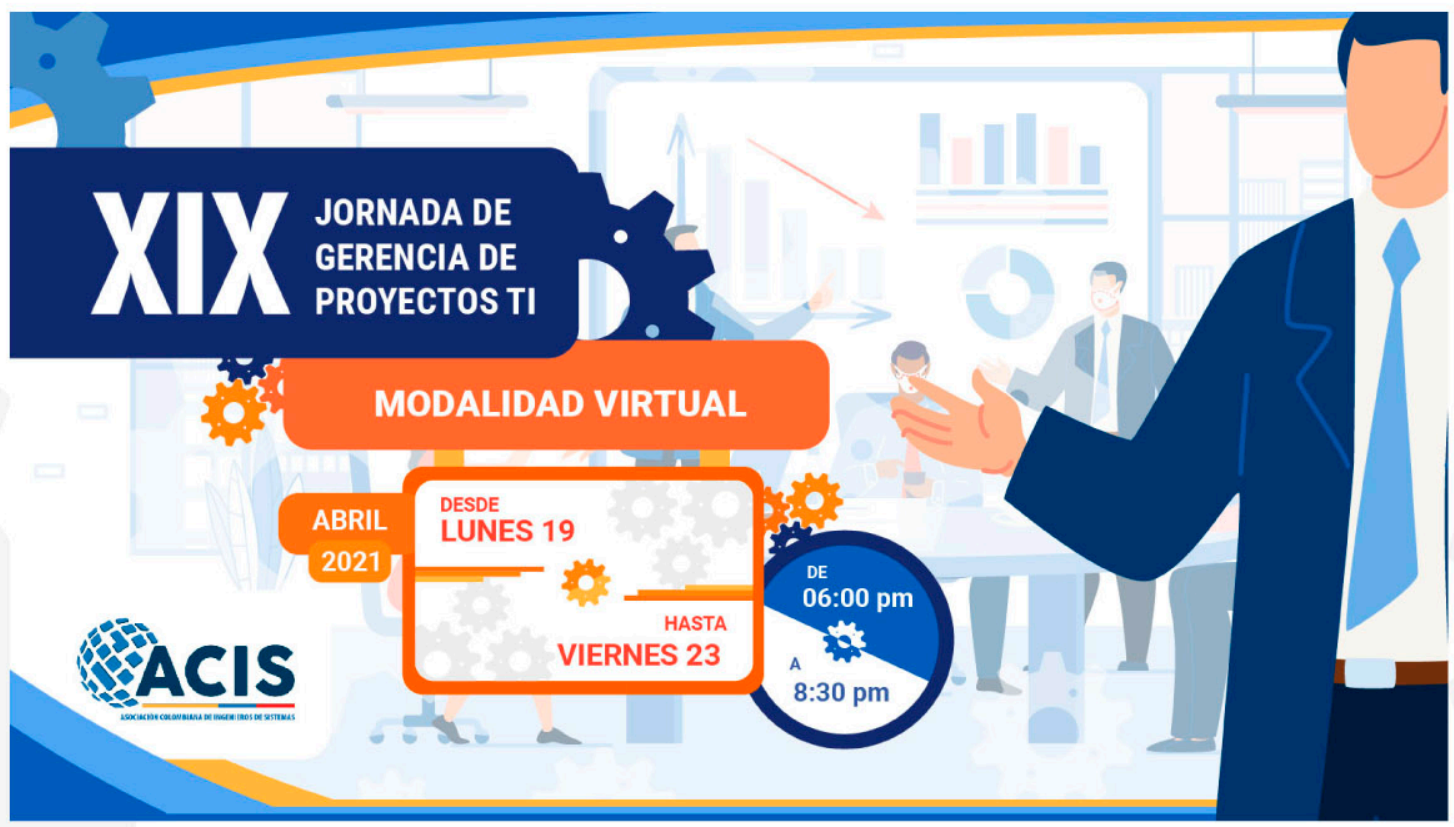

Después de un año 2020 complejo en el que el mundo cambió y nos vimos obligados a transformar nuestra forma de trabajar, de ver los negocios, y de abordar la vida, hubo un factor común que enfrentamos quienes trabajamos en TI: gestión de proyectos y de operación disruptivos para atender una transformación digital acelerada.

Estaremos revisando con nuestros conferencistas algunos temas como: modelos de gestión de proyectos abordados desde la innovación (Desing Thinking), modelos de empresa que se fundamentan en agilisimo, recuperación de proyectos en crisis, entre otros temas, todos con una nueva mirada; la de una pandemia que nos obligó a repensarnos y en algunos casos a reafirmarnos en nuestros conceptos y prácticas.

Bienvenidos a la XIX Jornada de Gerencia de Proyectos de TI

Coordinadores Académicos:

Hilda Cristina Chaparro López, MSc, PMP

Alberto Domínguez Sandoval, MSc, PMP, PMI ACP 